\title{
Functional Grammar and Its Implications for English Teaching and Learning
}

\author{
Zhiwen Feng $^{1}$ \\ ${ }^{1}$ School of Foreign Languages, Yunnan Normal University, China \\ Correspondence: Zhiwen Feng, School of Foreign Languages, Yunnan Normal University, Kunming, Yunnan, \\ China. Tel: 86-138-8859-9089. E-mail: fengzhiwen1228@163.com
}

Received: July 5, 2013 Accepted: July 30, 2013 Online Published: September 4, 2013

doi:10.5539/elt.v6n10p86 URL: http://dx.doi.org/10.5539/elt.v6n10p86

\begin{abstract}
Functional grammar has received more and more attention from domestic scholars in the world of linguistics since 1970s, but it is still new to most EFL teachers. In spite of controversies about its applications into classroom teaching, this new grammar model has its own advantages and can facilitate EFL students to achieve academic success. This paper, based on current literature, examines and analyzes the following issues: the nature of functional grammar, the key concepts of functional grammar, the fundamental differences between traditional grammar and functional grammar, and the implications for English teaching and learning. The purpose of this paper is to help EFL teachers have an overall understanding of the theory and key concepts of functional grammar as well as the positive role functional grammar plays in school contexts.
\end{abstract}

Keywords: functional grammar, traditional grammar, EFL teachers, EFL students

\section{Introduction}

Functional grammar, a grammar model developed by Michael Halliday in the 1960s, while still new to most EFL teachers, has aroused great interest for researchers. In spite of controversies about its application into classroom teaching, (e.g. too many concepts and terms) functional grammar is gaining popularity in schools and is helpful for EFL students to achieve success. In the field of language teaching, functional grammar has more applications to speaking and writing. The main reason is that functional grammar serves the communicative purpose of EFL students' learning the English language and provides the opportunity for EFL students to recognize the linguistic features of the language, which they need to learn for success at school (Schleppegrell, 2004).

This paper is based on literature review and discusses four questions: What is functional grammar? What are the key concepts of functional grammar? What are the fundamental differences between traditional grammar and functional grammar? What are the implications for English teaching and learning? The purpose of this paper is to help EFL teachers have an overall understanding of the theory and key concepts of functional grammar, and to realize its importance for EFL students to achieve success in school contexts or academic registers.

Bloor (2005) argues that a language teacher ought to know as much as possible about the language and that knowledge should include, as a major component, knowledge about grammar; and that given a good command of the target language, a non-native speaker with appropriate professional training and a good understanding of the way that the language works can do an excellent job. Accordingly, through a detailed discussion of functional grammar, this paper will facilitate the present language teaching and learning.

\section{What is Functional Grammar?}

Functional grammar, based on systemic linguistics, emphasizes the way spoken and written language operate in different social situations. In particular, it is very useful in showing how texts work beyond the level of the sentence, how different texts are structured, and how language varies to suit the purpose of the users. It takes on a descriptive approach and focuses on groups of words that function to make meanings.

In his classic book An Introduction to Functional Grammar, Halliday (1994) points out that functional grammar is so-called because its conceptual framework is a functional one rather than a formal one. It is functional in three distinct senses: in its interpretation (1) of texts, (2) of the system, and (3) of the elements of linguistic structures. In the first sense, functional grammar is designed to account for how the language is used. Every text (everything that is said or written) unfolds in some context of use. Over tens of thousands of generations of 
constant use, language has shaped into a system which can satisfy human needs. Therefore, "A functional grammar is essentially a 'natural' grammar, in the sense that everything in it can be explained, ultimately, by reference to how language is used" (Halliday, 1994, p. xiii). In the second sense, the fundamental components of meaning in language are functional components. According to the analysis of Halliday, all languages are organized around two kinds of meanings, the 'ideational' (to understand the environment), and the 'interpersonal' (to act on the others in it). Combined with these two is a third component, the 'textual', which breathes relevance into the other two. These three components are called metafunctions in the terminology of FG theory. In the third sense, each element in a language is explained by reference to its function in the total linguistic system. Accordingly, "a functional grammar is one that construes all the units of a language - its clauses, phrases and so on. In other words, each part is interpreted as functional with respect to the whole" (Halliday, 1994, p. xiv).

Based on Halliday's model, Thompson (1996) explains the three metafunctions of functional grammar in an informal way as follows: 1) we use language to talk about our experience of the world, including the world in our minds, to describe events and states and the entities involved in them. 2) We also use language to interact with other people, to establish and maintain relation with them, to influence their behavior, to express our own viewpoint on things in the world, and to elicit or change theirs. 3) Finally, in using language, we organize our messages in ways which indicate how they fit in with the other messages around them and with the wider context in which we are talking or writing.

Similarly, Martin, Matthiessen and Painter (1997) define functional grammar as a way of looking at grammar in terms of how grammar is used. In the field of linguistics, formal grammar, which is an alternative to functional grammar, is concerned with the ways our genes constrain the shape of our grammar, and thus constrain what a person can and cannot say. Contrastively.

Functional grammar is not genetically oriented to our neurophysiology in this way. Rather, it focuses on the development of grammatical systems as a means for people to interact with each other - functional grammar sees grammar as shaped by, and as playing a significant role in shaping, the way we get on with our lives. Its orientation is social, in other words, rather than biological (Martin, Matthiessen \& Painter, 1997, p. 1).

Therefore, functional grammar, based on cultural and social contexts, is very useful for describing and evaluating how language can be used to write and speak more appropriately and effectively. Using functional grammar can help us to read more carefully and critically.

\section{Key Concepts in Functional Grammar}

Functional grammar has many concepts, so it is not easy to provide a clear and ordered explanation of them. Different books arrange the concepts in different orders. Those charts, tables or paradigms, plus considerable terminology, look terrible for new learners. In the book A Theoretical Grammar of English, Xu (1993) academically introduces the theory and its concepts in detail. However, this paper intends to explain the key concepts in a simple way so that EFL teachers can get a vivid picture of functional grammar and how to apply it.

In traditional grammar, there are 10 parts of speech: noun, verb, adjective, adverb, pronoun, number, article, preposition, conjunction, and interjection. Then each of these ten classes can be divided into subcategories based on their functions. In functional grammar, these classes of words do not disappear. However, functional grammar places English words into four big groups: noun group, verb group, adjective group, and prepositional group (See Example 1). In addition, traditional grammar analyzes a sentence structure into subject, predicate, object, attributive, adverbial, and complement, while functional grammar gives a clause different functional labels depending on three kinds of metafunctions (See Example 2).

Example 1.

\begin{tabular}{llllllll}
\hline \multicolumn{2}{l}{ Traditional grammar } \\
\hline His & good & friend & wrote & this & book & in & America. \\
Pron. & Adj. & N. & V. & Pron. & N. & Prep. & N. \\
\hline
\end{tabular}




\begin{tabular}{lll}
\hline Functional grammar & & \\
\hline His good friend & wrote this book & in America. \\
Nominal group & Verbal group & Prepositional group \\
\hline
\end{tabular}

Example 2.

\begin{tabular}{lll}
\hline Traditional grammar & & \\
\hline This bridge & was built & before the $19^{\text {th }}$ century. \\
Subject & Predicator & Adverbial \\
\hline
\end{tabular}

\begin{tabular}{lll}
\hline Functional grammar & & \\
\hline This bridge & was built & before the $19^{\text {th }}$ century. \\
Theme & Rheme & \\
\hline
\end{tabular}

\begin{tabular}{lll}
\hline Functional grammar & & \\
\hline This bridge & was built & before the $19^{\text {th }}$ century. \\
Goal & Process & Circumstance \\
\hline
\end{tabular}

From these two examples, we can see that functional grammar has its own characteristics. To serve its communicative purpose, its concepts are quite different from traditional grammar. Based on current books on functional grammar, its key concepts include: functions and systems, hierarchical ranking of units, word order, word groups, functions of the sentence, theme, mood, transitivity, and the clause complex. The major and important concepts will be explained in the following section.

\subsection{Functions and Systems}

Functional grammar looks at how language works in terms of the functional relationships of its constituent parts, and systems of choice which we make whenever we use language. The term "functional" is used because it describes the approach which sees grammatical categories in terms of their communicative functions. Its system network is like a computer program. When we start to run the program, the computer presents us with a "menu" of possible functions which the program can perform. After we select one of these functions, we will have sets of options to choose from. Let's take the following language "menu" as an example.

\begin{tabular}{l}
\hline Statement \\
\hline Question \\
Exclamation \\
Greeting \\
Request \\
Suggestion \\
\hline
\end{tabular}

When we speak an utterance, we must choose whether we wish to give it the form of a statement, question, exclamation, greeting, request, suggestion, etc. Once we choose to form a question, we then have a range of possible interrogative options in English, such as starting with Wh-, How, Do/Does, Will/Would, or with some other verbs by making inversions. Or we could simply let intonation and context do the job and retain the basic word order of a statement. Thus, selection of A is the entry condition of B, and selection of B will be the entry condition of $\mathrm{C}$, and so on.

Such choice is not arbitrary or whimsical, and we do in fact have good reasons for choosing one form instead of another. Our grammatical choices will be determined by various stylistic and contextual factors; for example, whether the speaker is referring to new or given information, the degree of formality and politeness involved and 
so on.

\subsection{Hierarchy of Linguistic Units}

Functional grammar relates grammatical categories to the communicative functions which they serve. These functions are seen to operate at different levels of organization in the language, and may be identified in terms of the constituent parts which go to form larger units. This implies a segmental principle of organization, in which larger units may be seen as being formed from smaller units and smaller units being combined to form the larger units. Take the following clause as an example: The little boys are working very hard on the lawn.

Here, two morphemes "boy" and "s" form one word "boys". Two morphemes "work" and "ing" form one word "working". Three words "the", "little" and "boys" constitute a word group which is called nominal group. In this clause, there are four word groups in all: nominal group (the little boys), verbal group (are working), adverbial group (very hard), and prepositional group (on the lawn). Also, in functional grammar there is still an adjective group like "quite interesting". Word groups then form the constituent parts of a clause. This hierarchical relationship can be vividly seen in the following model:

\section{CLAUSE}

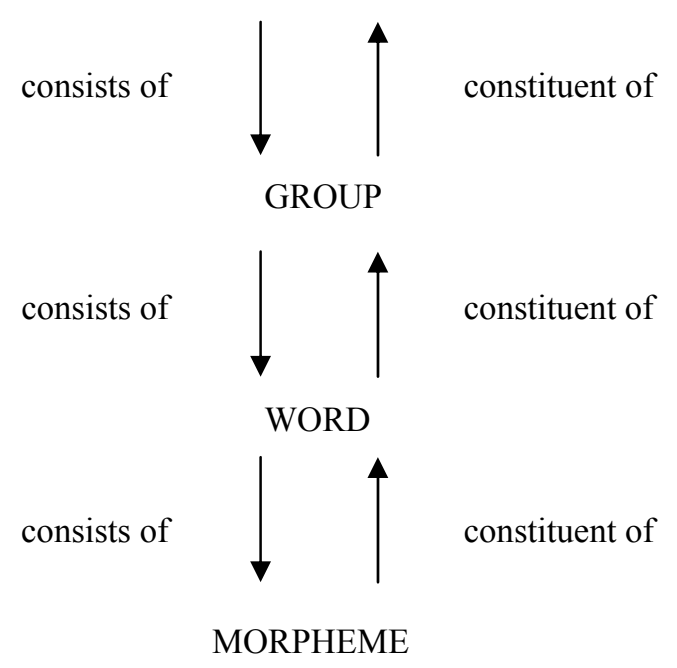

Figure 1. Hierarchy of linguistic units

Thus, in functional grammar, a clause is the highest grammatical unit, made up of one or more groups; each group is made up of one or more words, and each word is made up of one or more morphemes, the morpheme being the minimal unit. This rank scale is the fundamental concepts in functional grammar.

\subsection{Clause and Sentence}

Although most books on functional grammar do not contribute a particular chapter to the concept of clause, it is of great importance. A clause is the highest unit of functional grammar. However, for EFL students, it is difficult to make a clear distinction between a clause and a sentence. Therefore, a comparison between a sentence and a clause has its significance in learning and using grammar.

In traditional grammar, a sentence is a self-contained syntactical unit, and is traditionally divided into two parts, subject and predicate. Or, a sentence is a grammatical unit that is composed of one or more clauses. Moreover, the meaning of the term "sentence" may be expanded to include elliptical material and nonproductive items. In addition, traditional grammar sentences can be classified into three kinds: a simple sentence, a compound sentence, and a complex sentence.

Compared with a sentence, a clause is a grammatical unit that includes, at minimum, a predicate and an explicit or implied subject, and expresses a proposition. Based on the definition of Halliday (1994), a clause is a composite entity, which is constituted not of one dimension of structure but of three (subject, actor, and theme). Each of the three functions construes a distinctive meaning. He labels them 'clause as message', 'clause as exchange', and 'clause as representation'. Therefore, the concept of a clause is quite different from that of a sentence. Discussion of their differences will make a long story. Here, we just compare their structures, which can be seen from the following examples. 


\begin{tabular}{lll}
\hline Examples & Clause & Sentence \\
\hline He can't lift the heavy bag. & 1 clause & 1 sentence \\
Go! & 1 clause & 1 sentence \\
Hello! & & 1 sentence \\
He kept quiet in order to avoid trouble. & 1 clause & \\
He came in, sat on a chair, and read a newspaper. & 3 clauses & 1 sentence \\
\hline
\end{tabular}

\subsection{Theme}

The system of theme belongs to the textual metafunction of the language. It is concerned with the organization of information within individual clauses and through this, with the organization of the larger text. Besides, every clause is organized as a message related to an unfolding text. The system of theme organizes the clause to show what its local context is in relation to the general context of the text it serves in. The system is concerned with the current point of departure in relation to what has come before, so that it is clear where the clause is located in the text-how its contribution fits in. In Working with Functional Grammar, Martin, Matthiessen and Painter (1997) explain that

This local context or point of departure is called theme. The rest of the message of the clause is what is presented against the background of the local context-it is where the clause moves after the point of departure. This is called Rheme. The clause as message is thus organized into Theme + Rheme. (And) the theme is realized by initial position in the clause and Rheme that follows. (p.21)

For example:

\begin{tabular}{ll}
\hline Theme & Rheme \\
\hline John's friend & came to see me yesterday. \\
Last night & a girl was drowned in this river. \\
Friends like that, & i can do without. \\
Next door & is an elementary school. \\
After the party, & where did you go? \\
Have you & finished your homework? \\
Leave & that door open. \\
\hline
\end{tabular}

Schleppegrell (2004) states that "Theme is a construct of functional grammar that reveals how a clause in English is organized as a message"(p.67). It occurs first in the clause, and serves as a point of departure. The theme of a clause sometimes is the subject of a clause, but the functions of subject and theme are not the same. The significance of the concept of theme is that theme in a clause is a point of departure for the development of a text. Following this point of departure, the text will be coherent and logical when we write and speak.

\subsection{Mood}

The system of mood belongs to the interpersonal metafunction of the language and is the grammatical resource for realizing an interactive move in dialogue (Martin, Matthiessen \& Painter, 1997). It governs the basic structural features of the sentence-whether the sentence chooses between declarative, interrogative or imperative forms. Thus, the mood system is the part of grammar which is most inherently linked with the roles which speakers adopt in the use of language. We can think of the way we use language interactively as a form of exchange, and we can understand the function of language in the following two ways: 1) where language serves as a means of exchanging goods and services, and influencing the behavior of others; 2) where language is itself the medium of exchange in the form of information.

In these interactive exchanges, we have to assume which roles may be appropriate when we are required to express requests for services or information, to provide information or service for someone else, to give instructions and warnings, to make demands, or to pay compliments, etc.. For example, each of the following alternatives has a different interactional status and each embodies an alternative mood choice: 


\begin{tabular}{ll}
\hline Example & Mood \\
\hline He came from a Southern city of China. & Declarative \\
Did he come from a Southern city of China? & Interrogative: Yes/No \\
Who came from China? & Interrogative: Wh- \\
Where did he come from? & \\
Don't do that again. & Imperative \\
\hline
\end{tabular}

Clearly, if we take a look at each of these as a possible move in a dialogue, we will find that one difference between them lies in the role the speaker takes. In other words, the role the speaker decides to take will determine which mood he will use in a dialogue or conversation. Since mood is a system, once a kind of mood is selected, sets of options are available for the speaker to choose from. The following is a summary system network of mood.

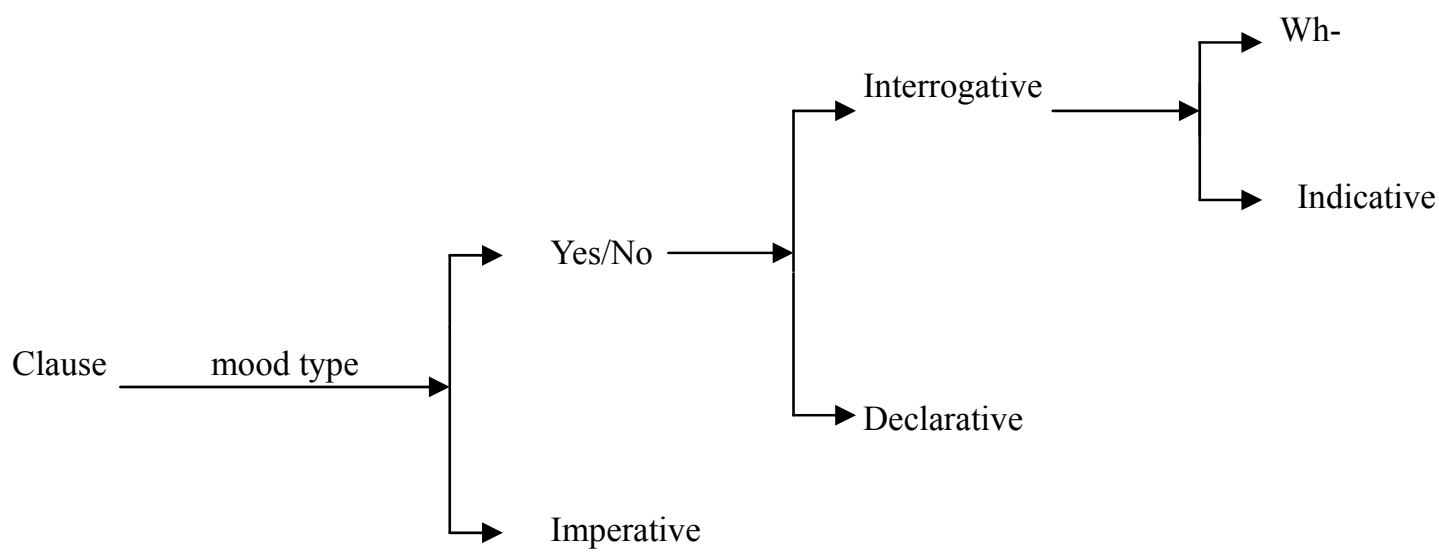

Figure 2. A diagram of mood system

\subsection{Transitivity}

The system of transitivity belongs to one mode of the ideational metafunction, that is, the experiential one. It is a resource for construing our experience in terms of configuration of a process, participants and circumstances. Thompson (1996) analyzes that when using language to interact with people, we clearly use it to talk about the world, either the external world, things, events, etc., or our internal world, thoughts, beliefs, feelings, etc. When we look at how language works from this perspective, we are focusing primarily on the content of a message. When we account for the content meanings, it is the role of experiential perspective in the grammar to allow us to do so.

In addition, the term transitivity will probably be familiar as a way of distinguishing between verbs according to whether to have an object or not. However, in functional grammar it is used in a much broader sense. In particular, it refers to a system for describing the whole clause, rather than just the verb and its object. It does, though, share with the traditional use a focus on the verbal group, since it is the type of process which determines how the participants are labeled. Although there are innumerable kinds of goings on and ways in which they can unfold, the grammar construes a small number of distinct types, each with its own particular characteristics. Altogether, the system of transitivity discriminates six different types of process in English. The three major ones are material, mental, and relational, each with a small set of subtypes. Also, there are three further process types, the behavioral, verbal, and existential. These six kinds of clause are illustrated in the following table. 


\begin{tabular}{ll}
\hline Process type & Example clause (process in bold) \\
\hline Material & The boy made a box. \\
Mental & She liked classical music. \\
Relational & Mary was strong. \\
Behavioral & She laughed \\
Verbal & He replied. \\
Existential & There was a house over there. \\
\hline
\end{tabular}

\section{Differences in Nature between Functional Grammar and Traditional Grammar}

As a new model of grammar, functional grammar is quite different from traditional grammar. Functional grammar focuses on the way language is put together so that meaning is communicated for particular purposes, and looks at a language as a system of meaning, while traditional grammar is concerned with the ways words are organized within sentences and looks at a language as a set of rules. In other words, functional grammar is different from traditional grammar in that it focuses on language as a meaning-making resource rather than as a set of rules (Schleppegrell, 2004).

Also, functional grammar provides us with tools for describing how language is used in varying, real-life contexts, and for understanding why a text is the way it is (Martin, Matthiessen \& Painter, 1997). It respects speakers' rights to make up their own minds about how they choose to talk, and it makes speakers explicitly aware of the choices they have available. On the other hand, traditional grammar is a prescriptive one, telling you what you can and cannot say and provides rules for correcting what are often referred to as grammatical errors. In addition, functional grammar is concerned with how the various bits of language in a text work together as part of a larger system in order to construct meaning, while traditional grammar is concerned with identifying the functions of words and word groups within sentences, without demonstrating how they contribute to the overall meaning in a text. At the same time, functional grammar is concerned with how language is used in a range of cultural and social contexts, while traditional grammar is mainly concerned with how to use language correctly in writing and speech.

In analyzing sentence and word, Halliday (1994) points out that traditional grammar stops at the sentence and there is a sense in which this does form an upper bound. However, for functional grammar, in terms of rank, there is no fixed upper limit. It treats the clause as the basic unit, while traditional grammar regards the sentence as the basic unit.

Besides the above analyzed differences between functional grammar and traditional grammar, there are still great differences between them, including the areas they cover, and terminology they use. However, the fundamental difference is that functional grammar is a meaning-based, descriptive one, and traditional grammar is a form-based, prescriptive one. In the field of language teaching and learning, their purposes and applications are thus quite different.

\section{Implications for English Teaching and Learning}

Functional grammar is more sociological in orientation. It is concerned with understanding the ways in which language is used for different purposes and in different situations, serving a communicative purpose of language learning. This is what EFL students really need. Most EFL students are taught traditional grammar, and know a lot of grammar rules. In their mind, a language is a set of rules. For a communicative purpose, this mindset should be changed. They need to know how to use language in different situations. In order to achieve academic success in school, they must be familiar with school-based texts. They should know the differences of modes and genres between spoken English and written English.

Through text analysis, functional grammar can offer EFL students "a way of seeing how meaning and form are related in the different options available in the grammatical systems of the English language, and know how knowledge is construed in school" (Schleppegrell, 2004, p. 1). For most EFL students, because of their poor English language experience at home, they often confuse informal or spoken English with formal or written English. Therefore, the great challenge for EFL students is "literate" texts, which have been described as decontextualization, explicit, and complex (Schleppegrell, 2004). In order to be familiar with literate texts, it is necessary for EFL students to know how language works in these texts. When writing his classic book, Halliday (1994) says that the aim of his book is to construct a grammar for purposes of text analysis: one that would make 
it possible to say sensible and useful things about any text, spoken and written, in modern English. Moreover, some projects about functional grammar are welcomed by students and teachers in some schools. In reality, integrating functional grammar in practical language teaching and learning is possible.

Beikoff (1996) gives a positive report in Daily Telegraph that functional grammar was successful when it was used to teach early literacy. He comments that functional grammar is not just a new type of jargon but another way of understanding sentences. It does not break a sentence up into discrete parts but links words that shape a purpose. In the book Genre,Text, Grammar: Technologies for Teaching and Assessing Writing, Knapp \& Watkins (2005) examine how the three aspects of language (genre, text and grammar) can be used as resources in teaching and assessing writing. They provide EFL teachers with some practical ideas for teaching the genres and grammar of writing across curriculum.

Recently, Chen Jing (2010) did a comparative study to examine the feasibility and efficacy of teaching functional grammar to college students. Results from his study indicate that the experimental group, who were taught functional grammar to analyze texts, achieved greater progress in writing than the control group who continued with traditional grammar at the general level. Particularly, at the specific levels of register, discourse and grammar, students in the experimental group made significant improvements. Chen Jing's research shows that "Functional grammar, the meaning resources for constructing discourse and the metalanguage employed by teachers and students to talk about written texts, can help students master English grammar from a semantic perspective based upon their former knowledge of traditional grammar, and apply it to language tasks to realize meanings in various structures"(p. 59) . In the same year, in the book Functional Grammar in the EFL Classroom, Lock \& Jones (2010) introduced six general procedures for language learners to notice, explore and practice grammar in context. After a detailed discussion of each procedure, Lock and Jones provided language teachers and learners two sample lesson plans together with sample texts. The procedures designed purposely illustrate how grammar can be taught through texts.

However, considering that learning functional grammar needs some basic knowledge and good analytical ability, the author of this paper thinks that it may be more successful when functional grammar is used to teach intermediate and advanced literacy. Schleppegrell (2004) argues that each subject area of schooling has its own different expectations in terms of the genres that students will read and write. Each genre is constructed through grammatical resources that construe the disciplinary meanings. Accordingly, functional grammar has a close relevance to the success of EFL students in school contexts.

When EFL teachers use functional grammar in their teaching, here are three suggestions: One is to make text analysis around clauses and word groups (noun groups, verb groups, adjective group, and prepositional group). At the same time, they need to try to avoid some functional labels. The author of this paper doesn't think it is a good idea to teach all the functional labels to students. The main purpose is to let students know how language works that way. The second suggestion is to let students deeply realize that grammar is a resource of making meaning and a subsystem of language. In functional grammar, there are many systems, such as mood system, verb system, and so on. This idea of language as a system is very important in helping EFL students to understand how language works. Last, making a comparison between functional grammar and traditional grammar would reinforce the understanding of functional concepts because most EFL students have been taught traditional grammar. They don't know what uses are appropriate or not, but they do know what uses are right or wrong.

\section{Conclusion}

Functional grammar has only a short history, but it has now come to be recognized as a major force in world linguistics. As EFL teachers, it is necessary to have a good knowledge about functional grammar because it is part of the English language and may bring a great change to EFL teaching and learning. Pedagogically, functional grammar, in spite of its terrible jargon, has its own advantages and can facilitate EFL students to achieve success in academic registers if EFL teachers can find a good way to teach its concepts in order. Also, it can help EFL students to achieve success in other subject areas like history and science. Besides its significance in teaching and learning, functional grammar has opened a wide research field in linguistics. With functional grammar, language teaching and learning will be more interesting and meaningful.

\section{References}

Beikoff, K. (1996). How functional grammar works. Daily Telegraph. Retrieved June 10, 2013, from http://minerva.ling.mq.edu.au/network/debates/DailyTelegraph.html

Bloor, T. (2005). Grammar of modern English. Fundamental Issues in Grammar. Retrieved March 10, 2010, 
from http://www.philseflsupport.com/grammar_issues.htm

Chen Jing. (2010). An Empirical Study of Applying Functional Grammar to College English Teaching. Foreign Languages in China, 7(3), 59-64.

Halliday, M. (1994). An Introduction to Functional Grammar (2nd ed.). New York, NY: Oxford University Press Inc.

Knapp, P., \& Watkins, M. (2005). Genre, Text, Grammar: Technologies for Teaching and Assessing Writing. Sydney: UNSW Press.

Lock, G., \& Jones, R. (2010). Functional Grammar in the EFL Classroom: Noticing, Exploring and Practicing. Publisher (United Kingdom): Palgrave Macmillan. Martin, J. R., Matthiessen, C. M. I. M., \& Painter, C. (1997). Working with Functional Grammar. New York, NY: St. Martin's Press, Inc.

Schleppegrell, M. J. (2004). The Language of Schooling: A Functional Linguistics Perspective. Mahwah, NJ: Lawrence Erlbaum Associates, Inc., Publishers.

Thompson, G. (1996). Introducing Functional Grammar. New York, NY: St. Martin's Press, Inc.

Xu Rumin. (1993). A Theoretical Grammar of English. Nanning: Guangxi People's Publishing House.

\section{Copyrights}

Copyright for this article is retained by the author(s), with first publication rights granted to the journal.

This is an open-access article distributed under the terms and conditions of the Creative Commons Attribution license (http://creativecommons.org/licenses/by/3.0/). 